\title{
Analgesic effect of topical sodium diclofenac $0.1 \%$ drops during retinal laser photocoagulation
}

\author{
Dov Weinberger, Yonina Ron, Henia Lichter, Irit Rosenblat, Ruth Axer-Siegel, \\ Yuval Yassur
}

\begin{abstract}
Aims-To evaluate the analgesic effect of topical sodium diclofenac $0.1 \%$ during retinal laser photocoagulation.

Methods-87 patients, 45 with proliferative diabetic retinopathy treated with two sessions of panretinal photocoagulation (group A), and 42 patients with nonproliferative diabetic retinopathy who underwent grid treatment of the posterior pole (19 bilaterally) (group B). Sodium diclofenac $0.1 \%$ or sodium chloride $0.9 \%$ drops were topically applied 30-135 minutes before laser treatment in a masked fashion. Patients who had two sessions were given the alternate drug in the second one. Pain level was evaluated immediately after laser treatment with the visual analogue scale (VAS). The results were statistically analysed.
\end{abstract}

Results-Patients in group A reported pain in $85 / 90$ sessions (94\%). The average pain level was $44.2 \%$ with sodium diclofenac $0.1 \%$ drops and $53.1 \%$ with sodium chloride $0.9 \%$ drops $(p=0.011$ by paired $t$ test). Patients in group $B$ reported pain in only $16 / 60$ sessions $(26.7 \%)$, and the pain level ranged from $10 \%$ to $60 \%$ regardless of the kind of drops used. There was no correlation in either group between level of pain and time interval from application of the drops to laser treatment (30-135 minutes) or average energy level used (100-500 mW).

Conclusion-Sodium diclofenac $0.1 \%$ is useful for pain reduction and should be applied before panretinal photocoagulation.

(Br F Ophthalmol 2000;84:135-137)

Ophthalmology, Rabin

Medical Center,

Beilinson Campus,

Petah Tiqva and

Sackler Faculty of

Medicine, Tel Aviv

University, Tel Aviv,

Israel

D Weinberger

Y Ron

H Lichter

I Rosenblat

R Axer-Siegel

Y Yassur

Correspondence to: $\mathrm{D}$ Weinberger, $\mathrm{MD}$, Department of

Ophthalmology, Rabin

Medical Center, Beilinson

Campus, Petah Tiqva 49

100 , Israel

Accepted for publication 22 September 1999
$0.1 \%$ was proved effective in patients undergoing scleral buckling and vitrectomy. ${ }^{9}$
In the present study, we evaluated the analgesic effect of sodium diclofenac $0.1 \%$ drops in retinal laser treatment.

\section{Patients and methods}

A prospective, double masked, crossover, randomised, clinical design was used. The study population included 87 patients, 45 (26 male, 19 female) with proliferative diabetic retinopathy treated with panretinal photocoagulation (PRP) (group A) and 42 (22 male, 20 female) with non-proliferative diabetic retinopathy and clinically significant macular oedema (group B) who received grid treatment of the posterior pole. None of the patients had undergone previous laser therapy. All patients in group A received two laser sessions (90 sessions); in group B, 23 were treated unilaterally (one session) and 19 bilaterally (one session per eye) (total 60). Forty one patients in group $\mathrm{A}$ and 13 in group B were taking $100 \mathrm{mg}$ salicylic acid regularly.

The sodium diclofenac $0.1 \%$ was preserved in thiomersal $0.04 \mathrm{mg}$ and stored in an identical bottle as the sodium chloride $0.9 \%$; the masked bottles were marked 1 and 2, respectively. For each patient, just before the first laser session, the first researcher selected one of the bottles from a table at random and applied the drops. For the second laser session (that is, all of group A and 19/42 of group B), patients initially given drops from bottle 1 (sodium diclofenac $0.1 \%$ ) were treated with bottle 2 (sodium chloride $0.9 \%$ ) and vice versa. (Both sodium diclofenac $0.1 \%$ and sodium chloride $0.9 \%$ are odourless and do not sting.) In addition, drops of tropicamide $0.5 \%$ and phenylephrine hydrochloride $10 \%$ were given to dilate the pupils, one drop of benoxinate hydrochloride $0.4 \%$ was applied just before laser treatment as a local anaesthetic. No anaesthetic injection was given. The second researcher (who applied the laser treatment with a contact lens) was masked to the drops given.

A double frequency YAG laser was used: wavelength $532 \mathrm{~nm}$, spot size $200 \mu \mathrm{m}$, exposure time $0.1 \mathrm{~ms}$, and energy level 100-500 $\mathrm{mW}$; the number of applications ranged from 20 to 1000 . Laser treatment was performed by the second researcher 30-135 minutes after administration of the analgesic agent.

Pain sensation was evaluated immediately after treatment by the third researcher, who was also masked to the drops given, with Scott's visual analogue scale (VAS).$^{10}$ The VAS consists of a $10 \mathrm{~cm}$ scale along which are 
Table 1 Comparison of average treatment parameters

\begin{tabular}{llll}
\hline Group & $\begin{array}{l}\text { Applications } \\
\text { (number) }\end{array}$ & $\begin{array}{l}\text { Energy level } \\
(\mathrm{mW})\end{array}$ & $\begin{array}{l}\text { Time interval } \\
\text { (minutes) }\end{array}$ \\
\hline $\begin{array}{l}\text { (A) Proliferative diabetic retinopathy } \\
\text { Sodium diclofenac 0.1\% drops }\end{array}$ & 544.3 & 322.8 & 68.3 \\
NaCl 0.9\% drops & 557.7 & 326.2 & 68.7 \\
p Value (paired $t$ test) & 0.730 & 0.912 & 0.944 \\
(B) Non-proliferative diabetic retinopathy & & & 70.5 \\
Sodium diclofenac 0.1\% drops & 147.4 & 253.5 & 71.3 \\
NaCl 0.9\% drops & 131.8 & 270.0 & 0.9 \\
p Value (paired $t$ test) & 0.450 & 0.617 & \\
\hline
\end{tabular}

arranged deepening shades of grey, from light to dark, where white represents no pain and very dark grey, the worst pain imaginable. Markings of the subjects on the scale are translated to a percentage from $0 \%$ (no pain) to $100 \%$ (worst pain).

All the data were masked and analysed only at the end of the study.

Two main effects were examined. (1) To determine the general analgesic effect of sodium diclofenac $0.1 \%$ during laser photocoagulation, pain ratings made by the individual patients after the first and second sessions with the alternate agents were compared. (2) To determine whether laser treatment of the posterior pole is less painful than peripheral treatment, the number of sessions for which patients in groups A and B reported pain were compared. The effects of number of laser applications, energy level, and time from analgesia to laser treatment were also evaluated.

Statistical analysis was performed with parametric tests ( $t$ and paired $t$ ), non-parametric tests (Wilcoxon and Mann-Whitney) and Pearson's $\chi^{2}$ and correlation tests. The statistical parametric tests are usually used when large numbers of patients are involved. In our series we used this test when the results of the entire group were analysed. The non-parametric test was used when the group was divided according to sex. Pearson's $\chi^{2}$ and correlation tests were used to determine the correlation between variables such as number of laser applications, energy level, and pain sensation.

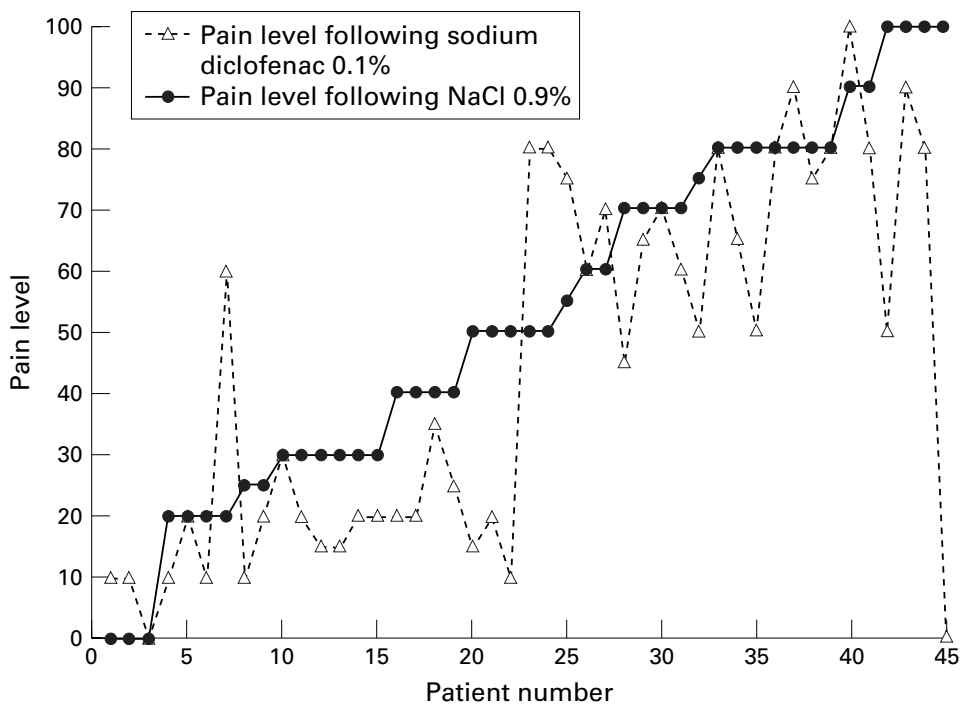

Figure 1 Scatter plot describing the difference in pain level in patients treated with sodium diclofenac $0.1 \%$ and sodium chloride $0.9 \%$ before panretinal photocoagulation (group $A$ ).
Table 2 Comparison of reported pain associated with peripheral and posterior pole laser treatments (by session)

\begin{tabular}{lll}
\hline Group & Pain & No pain \\
\hline B, NPDR Posterior pole treatment & 16 & 44 \\
A, PDR Peripheral treatment & 85 & 5 \\
p Value & 0.000 & \\
\hline
\end{tabular}

\section{Results}

In groups $\mathrm{A}$ and $\mathrm{B}$, the number of laser applications, energy levels used, and time from application of the analgesia or placebo to the laser treatment (Table 1) were not significantly different.

In group A, patients reported no pain in only five of the 90 laser sessions (6\%) regardless of the analgesic agent used. In all the other 85 sessions pain was reported. The mean reported level of pain was $44.2 \%$ when sodium diclofenac $0.1 \%$ drops were used and $53.1 \%$ when sodium chloride $0.9 \%$ drops were used (Fig 1); this difference was statistically significant ( $\mathrm{p}=0.01$ by paired $t$ test). However, nine patients out of 45 had more pain when using sodium diclofenac than using sodium chloride, and seven patients had no difference in perceived pain when using either of the drops. Division of the patients by sex yielded a $50.7 \%$ level of pain for males and $35.0 \%$ for females with sodium diclofenac $0.1 \%$ drops ( $p=$ 0.0593 by Mann-Whitney test), and levels of $56.34 \%$ and $48.68 \%$, respectively, with sodium chloride $0.9 \%$ drops ( $\mathrm{p}=0.320$ by MannWhitney test). When the levels of pain reported by females and males separately with sodium diclofenac $0.1 \% v$ sodium chloride $0.9 \%$ were compared, a significant difference was noted for females ( $p=0.0437$ by Wilcoxon test), but not for males ( $p=0.1023$ by Wilcoxon test). There was no correlation between degree of pain and either interval to treatment or average energy level used for either agent, or between degree of pain and use of salicylic acid.

In group B, patients reported no pain in 44 of the 60 laser sessions $(73.3 \%)$. In the remaining 16 sessions $(26.7 \%)$, the degree of pain ranged from $10 \%$ to $60 \%$ regardless of the kind of drops used. The difference in the number of sessions associated with pain between groups $\mathrm{A}$ and $\mathrm{B}$ was significant $(\mathrm{p}=$ 0.000 by Pearson's $\chi^{2}$ test) (Table 2 ).

\section{Discussion}

The present study evaluated the analgesic effect of the NSAID sodium diclofenac during retinal laser photocoagulation. The underlying mechanism for the analgesic effect of NSAIDs is believed to be their inhibition of the arachidonic acid cascade. The arachidonic acid cascade divides into the cyclo-oxygenase and the lipo-oxygenase pathways. The main products of the cyclo-oxygenase pathway are prostaglandins which cause miosis, an increase in vascular permeability of the blood ocular barriers, and changes in intraocular pressure. Prostaglandins also possess chemokinetic activity and take part in maintaining and amplifying the cellular and humoral phases of the inflammatory response, during which several mediators are released that stimulate 
pain producing nerve fibres. Leukotrienes are the end products of the lipo-oxygenase pathway. They are known to cause chemotaxis, chemokinesis, exudation of plasma, and stimulation of phospholipase A.

Indomethacin, which belongs to the indole chemical class and was the first topical NSAID to be used in ophthalmology, significantly decreases levels of prostaglandin E2 in the human cornea, where highest concentrations of the drug are found. ${ }^{11}$ Sodium diclofenac $0.1 \%$ belongs to the phenylacetic acid chemical class and appears to have a dual effect on the arachidonic acid cascade, since it also regulates the lipo-oxygenase pathway at a higher concentration. ${ }^{12}$ When applied topically, the drug penetrates the cornea and aqueous quite easily. The highest average concentration of the drug to be found in the aqueous humour was $82 \mathrm{ng} / \mathrm{ml}$ at 2.4 hours after instillation. ${ }^{13}$ Topical sodium diclofenac acts on the posterior segment of the eye either by diffusion into the vitreous from the aqueous or by "desensitisation" of the entire distribution of the trigeminal nerve fibres around the globe.

In this work, because pain sensation is subjective and its quantification also subjective, we used the VAS, which has been found to be correlative and reproducible. ${ }^{10}$ The major finding of this study was the significantly lower estimation of self reported pain level in the PRP patients pretreated with sodium diclofenac $0.1 \%$ drops than with sodium chloride $0.9 \%$ drops. Although nine patients out of 45 had more pain when using diclofenac than using sodium chloride and seven patients had similar levels of pain using both treatments, this was outweighed by the 29 who had less pain when using diclofenac (Fig 1). Though some patients reported low levels of pain and others high levels, the sensation was usually lower when sodium diclofenac was applied. The estimation of pain did not change in relation to number of applications (20-1000), energy level used (100-500 mW), or interval from application of the drops to laser treatment (30-135 minutes). This was true for the whole cohort and for the treatment groups.

Another important observation, which is clinically well recognised but statistically unproved, is that treatment of the posterior pole is associated with no or only mild or negligible pain. The absence of pain is probably related to the lower power levels used for grid photocoagulation. Indeed, in this study the average power per pulse used for macular photocoagulation was $253 \mathrm{~mW}$ in the diclofenac group and $270 \mathrm{~mW}$ in the sodium chloride group; whereas the average power used for peripheral treatment was $322-328 \mathrm{~mW}$ and $326 \mathrm{~mW}$, respectively.

In summary, the lower degree of pain reported by individual patients after sodium diclofenac analgesia compared with sodium chloride suggests that sodium diclofenac $0.1 \%$ is useful in the reduction of pain and is recommended for PRP. In addition, during pretreatment, clinicians should take into account that procedures involving the peripheral segments are more painful than those in the posterior segments.

1 Seitz B, Sorken K, LaBree LD, et al. Corneal sensitivity and burning sensation. Comparing topical ketorolac and diclofenac. Arch Ophthalmol 1996;114:921-4.

2 Szerenyi K, Sorken K, Garbus JJ, et al. Decrease in normal human corneal sensitivity with topical diclofenac sodium. Am f Ophthalmol 1994;118:312-15.

3 Kaiser PK, Pineda R II, Bhistikul R, et al. A comparison of pressure patching versus no patching ( \pm Voltaren) in corneal healing and comfort after corneal abrasions. corneal healing and comfort after
Ophthalmology 1994;101(Suppl): 73 .

4 Salz JJ, Reader AL III, Schwartz LJ, et al. Treatment of corneal abrasions with soft contact lenses and topical diclofenac. $\mathcal{F}$ Refract Corneal Surg 1994;10:640-6.

5 Fry LL. Efficacy of diclofenac sodium solution in reducing discomfort after cataract surgery. F Cataract Refract Surg 1995;21:187-90.

6 Epstein RL, Laurence EP. Effect of topical diclofenac solution on discomfort after radial keratotomy. $\mathcal{f}$ Cataract Refract Surg 1994;20:378-80.

7 Herchel MK, McDonald MB, Ahmed S, et al. Voltaren for treatment of discomfort after excimer ablation. Invest Ophthalmol Vis Sci 1993;34(Suppl):893.

8 McDonald MB, Herchel MK, Ahmed S, et al. Effect of Voltaren and FML drops in post-excimer laser photorefractive keratectomy therapy. Invest Ophthalmol Vis Sci 1993;34(Suppl):803.

9 Lesnoni G, Coppe AM, Manni G, et al. Analgesic effect of topical diclofenac versus betamethasone after posterior topical diclofenac versus betamethas.

10 Scott J, Huskisson EC. Graphic representation of pain. Pain 1976;2:175-84.

11 Koay P. The emerging roles of topical non-steroidal anti-inflammatory agents in ophthalmology. $\mathrm{Br} \mathcal{F}$ Ophthalmol 1996;80:480-5.

$12 \mathrm{Ku} \mathrm{EC,} \mathrm{Lee} \mathrm{W,} \mathrm{Kothari} \mathrm{HV,} \mathrm{et} \mathrm{al.} \mathrm{Effect} \mathrm{of} \mathrm{diclofenac}$ sodium on the arachidonic acid cascade. Am $f$ Med 1996;80(Suppl):18-23.

13 Ellis PP, Pfoff DS, Bloedow DC, et al. Intraocular diclofenac and flurbiprofen concentrations in human aqueous humor following topical application. F Ocular Pharmacol 1994;10: 677-82 